Article

\title{
Sustainable Government Enterprise Architecture Framework
}

\author{
Montree Thirasakthana (1) and Supaporn Kiattisin *(1) \\ Faculty of Engineering, Mahidol University, Nakorn Pathom 73170, Thailand; montree.thi@student.mahidol.ac.th \\ * Correspondence: supaporn.kit@mahidol.ac.th; Tel.: +66-81-866-4207
}

Citation: Thirasakthana, M.;

Kiattisin, S. Sustainable Government Enterprise Architecture Framework.

Sustainability 2021, 13, 879.

https://doi.org/10.3390/su13020879

Received: 16 December 2020

Accepted: 13 January 2021

Published: 16 January 2021

Publisher's Note: MDPI stays neutral with regard to jurisdictional claims in published maps and institutional affiliations.

\begin{abstract}
The suitable utility of driving the enterprise architecture exercise is to utilize the enterprise architecture framework as the fundamental guidance. But there are some challenges of applying those frameworks for government and their agencies because most of the frameworks have concentrated focus for the private sector which some fundamentally requirement of government would be specifically different. This paper aims to propose that the sustainable government enterprise architecture framework specifically applies for the national strategic planning in the optimum exercise process and clarity guidance for the information technology organization being able to transform and improve their services for an achievable adaptation efficiency, simplification, cost management, collaboration, shareability, and standardization which accommodate the rapidly changing service usability on digitalization known as "e-Government." The fundamental design idea of this proposed framework has identified five keys principles, which are (1) legislation support, (2) top-down target architecture, (3) architecture governance, (4) shared services, and (5) cross-organization collaboration that would be considered as the key critical success factors for achieving the exercise. The overall response of the specific expert survey of this proposed framework has demonstrated the consensus responded at 90 percentage agreeable, which would strongly consider this framework applicable for groups of developing countries as the baseline framework for their digitalized transformation.
\end{abstract}

Keywords: enterprise architecture framework; government enterprise architecture; sustainable government; e-Government

\section{Introduction}

Since the 1980s, most practitioner and scientific enterprises have recognized the contribution of an enterprise architecture (EA) [1] as the key criteria of improving enterprise ontology or enterprise re-engineering [2] by concentrating in reshaping information technology landscapes in order to steer the organizational strategic execution and its operation. Specifically, in the national public services, there are a series of strategic initiatives for transforming from "Government Public Services," which intensively require physical accessibilities, having physical interaction in between citizen and government officer to "e-Government Public Services," which mainly presented by internet accessibilities using any mobility devices at any times and anywhere, having all digitalization processes with less of people interaction each other. The typical key improvement in the public services is to emphasize on digital enablement whereby the overall service offering would be concentrated in simplification of usage adoption, standardization of operation procedure for commonality services, strengthen in security and privacy of data protection, efficiency of cost management, and improving of time consumption for people who request for services. In contrast, the adoption efficiency of enterprise architecture to address those strategic goals is still struggled in the reason of having fragmentation execution for each agency organization; also, each of them performs isolation and redundancy development, and having overlapping service functions [3]. More importantly, the understandability of usability on the practical enterprise architecture framework is still challenged, being viewed as a complexity utility [4] and lack of fruitfulness for accommodating the fundamentals of the government culture, which might need to serve the committed political agenda that 
is being changed according to the level of stabilization of that government. There is no certainty of normative standardization for those operation procedures on the government direction or governance as per the complexity and understandability of the EA framework in principle, which would be reflected to the capability of design, fragmented maintenance, high complexity, and cost, especially supporting the new strategic announcement, new request of enforcement, regulatory, or compliance being adopted.

There are several researchers who have proposed the exercise frameworks and transformation methods that are relevant to serve a modernization of the government in public services as the e-government capability. The researchers have proposed the encouraging of interoperability adoption [3,5,6], agile framework [7], Supply-Chain Operations Reference based [8], or lean theoretical [9] in combination with practical enterprise architecture frameworks like The Open Group Architecture Framework (TOGAF) [10] or The Zachman Framework For Enterprise Architecture (ZFEA) [11]. In addition, there are several organizations at the government of developed countries, or their agencies have also implemented their own enterprise architecture framework as country or owned organization specific by adopting and refining on those particular practical enterprise architecture frameworks with legislation or governance enforcement like Federal Enterprise Architecture framework (FEAF) [12] or European Statistical System Enterprise Architecture Reference Framework (ESS EARF) [13]. The benefit realization of those specific governments has been recognized as achievable establishment of enforcing the execution framework addressing the strategic target of public administrative services with sustainable information technology landscapes according to the design fundamental. Importantly, those achievable has been adapted and improved their exercise guideline in the series of version with multi-years evolution, specifically within their organizations. Thus, in comparing with the group of developing countries who have purely adopted those practical enterprise architecture frameworks like TOGAF or ZFEA without truly understanding, inappropriate refinement, uncertain guidance, and no legislation enforcement for example of Thailand Government enterprise architecture policy which each agency department has been required to establish the target architecture on their owned decision and method for example of an adoption of Digital Government Agency (DGA )Enterprise Architecture Plan [14].

This article objective is to fulfill the gap of the proposed sustainable government enterprise architecture framework for government by addressing the new comprehensive enterprise architecture framework that would be the solid guidance for developing countries being able to effectively adopt this framework appropriately and efficiently with a more sustainable manner.

This article has been structured with four major sections which begins with the introduction in Section 1, then followed by all related topics of enterprise architecture framework. Section 2 has mentioned about literature review findings, with the main searching scope concentrated in "Enterprise Architecture", "Enterprise Architecture Framework", "Interoperability", “Enterprise Ontology", "E-Government", “E-Government Adoption and Barrier", "E-Participation" and "Citizen Centricity" including the proposed research methodology and the proposed sustainable government enterprise architecture framework. Section 3 concludes the review response in the statement findings, including the summary of research discussion and presenting the case study of exercise on identifying target architecture of Thailand's Land Transport. Finally, Section 4 proposes the research conclusion.

\section{Materials and Methods}

As mentioned in the previous section, the key objective of proposing the sustainable government enterprise architecture framework is to comprehensively provide the clear guidance of executing the enterprise architecture framework for government or public administrative offices being able to effectively adopt with achievable results in the areas of standardization, services sharable, and cost efficient. There are several key reviewing areas that would lead to better understanding on the fundamental approach of enterprise architecture principal and its evolution in the proposed execution frameworks. The fact 
findings below have briefly described the related matter information leading the idea of this paper.

\subsection{Fundamental Needed of Achievable in Information Technology Enablement}

The fundamental requirement of executive management emphasis on Chief Information Officer level (CIO) who manage the information technology portfolio has indicated several valid points that typically Information Technology management in general would be targeted to achieve, especially leading by the exercise contribution of enterprise architecture. The survey has performed with several CIOs with the list of survey deliverable by priority ranking as per described in Table 1 [15].

Table 1. The Survey Result.

\begin{tabular}{|c|c|}
\hline $\begin{array}{c}\text { Survey } \\
\text { Ranking }\end{array}$ & Survey Result of CIO Expectation \\
\hline 1 & $\begin{array}{l}\text { Decrease the cost related to the business organization, such as cost for personnel in } \\
\text { the business organization }\end{array}$ \\
\hline 2 & $\begin{array}{l}\text { Improve the quality of the interplay between the IT organization and the business } \\
\text { organization, such as support, helpdesk, and end-user training }\end{array}$ \\
\hline 3 & $\begin{array}{l}\text { Provide new computer aided support to the business organization, such as new } \\
\text { functionality, new information, and communication means }\end{array}$ \\
\hline 4 & $\begin{array}{l}\text { Improve the quality of the IT systems, such as security, performance, availability, } \\
\text { reliability, quality of data, and correctness of functionality }\end{array}$ \\
\hline 5 & $\begin{array}{l}\text { Improve the quality of existing services or products that the business organization } \\
\text { provides to the customer }\end{array}$ \\
\hline 6 & $\begin{array}{l}\text { Improve the quality of operation and maintenance, development, and acquisition of } \\
\text { IT systems }\end{array}$ \\
\hline 7 & $\begin{array}{l}\text { Develop new services or products that the business organization provides to } \\
\text { the customers }\end{array}$ \\
\hline 8 & $\begin{array}{l}\text { Improve the maintainability and modifiability, e.g., by improving interfaces, } \\
\text { introducing middleware, and standardizing protocols and products }\end{array}$ \\
\hline 9 & Decrease the costs related to hardware and software \\
\hline 10 & $\begin{array}{l}\text { Decrease the costs related to the IT organization, such as wages and training for } \\
\text { IT staff }\end{array}$ \\
\hline 11 & $\begin{array}{l}\text { Provide new IT based solutions to the IT organization, such as administrative tools, } \\
\text { b-logs, and backup tools }\end{array}$ \\
\hline
\end{tabular}

In the survey findings, most management expectations in summary have been concentrated in several dimensions which could be summarized as better cost management, better collaboration in between businesses and IT, and better architecture and solution. The survey results are still challenged up until today for the organization that would expect to improve their information technology landscapes suited with their business operation and performance of their organization.

\subsection{Enterprise Architecture and Enterprise Architecture Frameworks}

The majority situations, the organization in general both of enterprise business and government, have operated their business or mission as per publicly commitment in the long periods of service duration even more prior than the establishment of an enterprise architecture which firstly proposed the commencement of information architecture by Zachman since the 1980s [16]. The mean of architecture has been identified by ISO/IEC/IEEE 42020 as fundamental concepts or properties of an entity in its environment and governing principles for the realization and evolution of this entity and its related life cycle processes [17]. Also, this standard has defined the definition of architecture framework as conventions, principles, and practices used by architecture-related activities that have been established within a specific domain of application or community of stakeholders. The adoption of the term architecture and its framework can be applied for both the system level and enterprise level. To enable the architecture practice, there are five key dimen- 
sions processes being proposed which are governance, management, conceptualization, evaluation, and elaboration. All dimensions would be relatively depended to each other, as shown in Figure 1.

The key components of designing the architecture frameworks as of today's availability is concentrated in the core processes, which give more emphasis on the stage of conceptualization, evaluation, and elaboration with more detail steps. For instance, the proposed enterprise architecture framework of the TOGAF [10], which guide the exercise steps of performing enterprise architecture activity. In the findings, TOGAF has clearly described how to conduct the enterprise architecture exercise concentrating in identifiable of the current baseline architecture and proposed target architecture covering business, information system and technology but in the form of project execution style, with the business strategy or business requirement generally having its own characteristic to dynamically change according to government strategy and public commitment. Also, the proposed TOGAF has fundamentally emphasized on descriptive deliverables of each exercise step; the practitioner may not be able to completely understand and conduct the exercises for all those required activities fulfilling those required descriptive as per mentioned by Dinh and Pekkola [4].

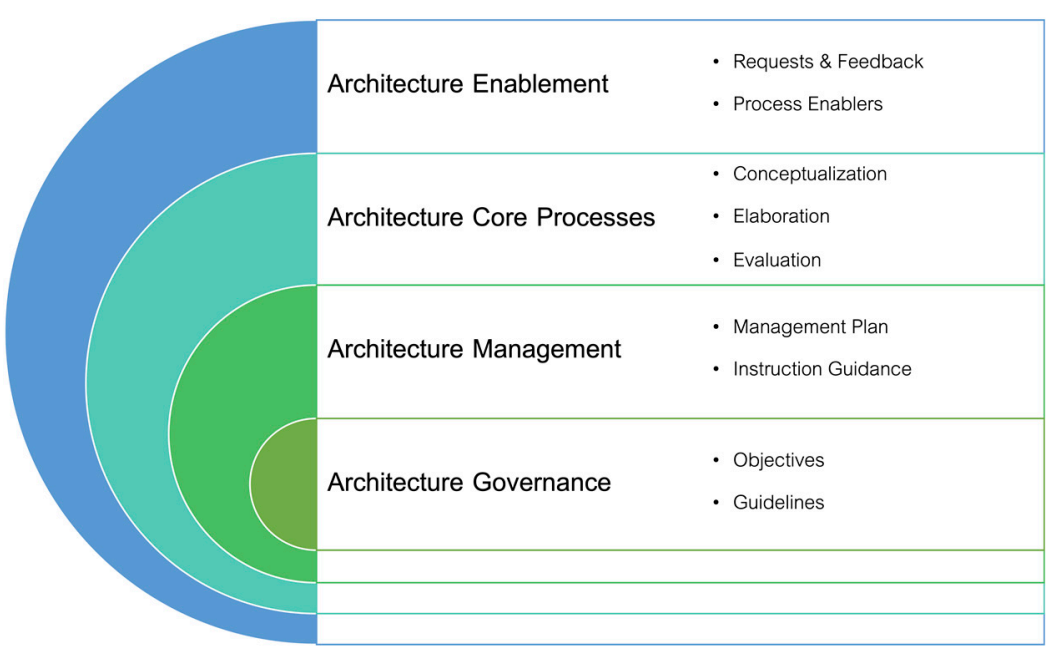

Figure 1. ISO/IEC/IEEE 42020 Architecture Enablement Processes.

For other practical enterprise architecture frameworks like Zachman Framework for Enterprise Architecture (ZFEA) [11] or Gartner Enterprise Architecture Framework (GEAF) [18], there are few identifiable commonalities conceptual of the framework methodology; the practitioner should mainly be able to describe the abstraction layer of the proposed target enterprise architecture landscapes and its execution roadmap. As mentioned earlier, the completeness of execution according to those frameworks might be challenged due to the clarity of understandability. And the context of availability enterprise architecture frameworks is still lacking level of detail for execution and managing dynamic changes in business strategic and planning appropriately [19]. More importantly for the government or public administrative offices, there is an analysis research for the systematic literature review on enterprise architecture in the public sector with the findings that there are still a limited number of researches that paid strong attention on concentrating over the adaptable of enterprise architecture framework to satisfy the public sector especially for the group of developing countries [4]. The analysis result was demonstrated that most researches have strongly concentrated on private sector or serving enterprise business which have more opportunities to successfully adopt the framework in collaboration with organization strategy. Thus, this paper has intended to comprehensively propose the sustainable government enterprise architecture framework that is suited to government or public sector, especially for developing countries by addressing the gap of survey or analysis findings $[20,21]$. 


\subsection{Enterprise Ontology and Alignment of Business to Information Technology}

The clear description of the term "Ontology" was defined in several definitions, and the fundamental concept can be defined into the same terminology. Thus, the simplest term of object-oriented perspective an ontology would be defined as the objects class and their corresponding class relationship whereby the class category has consisted with seven kinds of class, which are subject, object, community, tools, rules, division of labor, and outcome [22]. The adaptation of ontology would be described as the capabilities, functionalities, and their interoperability, such as the application packages which would be described in a single application or set of applications within the ecosystem. Consideration of the term "Enterprise Ontology," O'Leary has also described that the enterprise ontology has comprised with five primary top-level classes called as meta ontology (entity, relationship, role, actor, and state), activities and processes, organization, strategy, and marketing. This means the comprehensive exercise of establishment of the enterprise ontology strategy for efficiency execution should necessarily incorporate all of those components.

The most successful criteria of deliverable information technology solution is to be able to comprehensively accommodate business operation as per strategically defined under the theorical of enterprise ontology. Hence, this would be a basic fundamental of working method for enterprise architecture in order to align and interpret the business strategic planning to the suitable information technology solution by practicality conceptual. There are several researches that have also mentioned business and information technology alignment, which expected increasing an efficiency of organization to achieve the improvement of decision making, better business process execution, or gaining incrementally customer satisfaction $[23,24]$. Presently, the challenge of performing alignment of business and information technology depends on the continuous alignment approach in order to support rapidly changing in the business and information technology strategic planning, which several new initiatives or innovations have been concentrated their focus on, such as the digital transformation program or digitalization era which would dramatically impact the ability of maintaining the deliverable capabilities in a much faster and more agile manner [2].

\subsection{Enterprise Architecture and Interoperability Framezork for e-Government}

The ultimate goal of establishing the enterprise architecture for government and its agencies has been targeted to renovate and modernize over the overall public service operating model in order to improve the level of citizen satisfaction and quality of life, better manage and control cost of investment, promote an inter-collaboration by serving the standardization of information shared service, and increase the capability of data protection under legislation. All these are directed to the commonality objective which is to transform the current government service capability to be e-government service capability, whereby introducing automated process, enablement of digital service channels, and comprehensively promote information shared services as open architecture under the control guideline of legislation. By doing this exercise as the strategic plan, the interoperability framework of each country has been developed $[25,26]$ and proposed of adoption in compensating with the exercise of enterprise architecture for strategically driving the e-government program [6]. The conceptualized of interoperability is to complete the entire operating model in comprised of multidimensional capabilities in coverage of policy, management, and technology while several agency organizations of government have considered interoperability as information technology enablement of information integration/sharing from one to another (Pardo et al., 2012). The adoption of e-government interoperability framework of those developed countries have demonstrated in some different context as per the comparison analysis [27]. The emphasis of this enforcement as the certainty guideline of implementing interoperability capability has brought up to the legislation as the federal policy such as the FEAF, which included the e-Government policy guideline into the framework itself. There are some samples of clear enforcement guideline of interoperability frameworks which promote European countries inclusion of 
European Commission. They had identified their intention to ensure the establishment of interoperability would address the ability of exchange and mutually use the information in between organizations [28]. The group of developing countries specifically on each agency organization are still fragmented adoption of an enterprise architecture framework for their internal organization improvement with uncertainty guidance of improving the interoperability approach [3].

\subsection{An Adoption of e-Government}

Comprehensively, the e-government capability has identified the fundamentally required level of articulation in connecting with the government strategic goal, whereas an enterprise architecture would play in the key role of critical driven in order to describe the abstraction roadmap and interoperability guideline. All those would accommodate in different challenges of their deliverable capability [29]. The proposed framework of e-government architecture which comprised four architecture layers (access layer, e-government layer, e-business layer, and infrastructure layer) would be the key driver in order to enable the public services conceptually. In the meantime, there are key barriers, which are IT infrastructure, security, privacy, IT skills, organizational issues, and cost. These barriers would be considerable factors of impact to the success of achieving the improvement of e-government intension, as well as some uncertainty of e-government policy and lack of expertise resources, including some constrains such as constitutional of legislation, jurisdictional, and collaboration [30-32]. With the surveying reported by World Market Research Center, there is 6 percentage of national e-government that could provide single one-stop service portal.

Ojo et al. has defined 11 maturity factors shown in Table 2 [33], being proposed for consideration as the key success driver of practically exercise on government enterprise architecture.

Table 2. Government Enterprise Architecture Maturing Factors by Ojo.

\begin{tabular}{cc}
\hline Factor Number & Factor Description \\
\hline 1 & Management Commitment/Support and Involvement \\
2 & Business Unit Participation/Alignment \\
3 & Governance Structure and Compliance (Legislation) \\
4 & Technical Skills and Development \\
5 & Policies and Processes \\
6 & External Support \\
7 & Change Management \\
8 & Functional Knowledge and Processes \\
9 & Communication \\
10 & Resources Availability and Organization \\
11 & Clear Vision and Goal/Strategy \\
\hline
\end{tabular}

\section{6. e-Government Proposed Architecture}

There are several architectures being proposed for accommodating the proposed public services by having some key considerable success of adoption. In fact, the proposed public service as the capability of e-government has been categorized into three kinds of categories, which are government to citizen, government to business, and government to government [34]. The fundamental of information availability of each category is dedicatedly designed, whereby the design for serving citizen would concentrate in general demographic, education, health, employment, income tax, and social welfare, such as the proposed unified data modelling and document standardization [35]. The concentration of business services would be more on corporate tax, custom, registration, and permits. Additionally, the definition of citizen centric would be the key consideration for improving the capability of public services, whereby the smart city would be presented in consisting with four key dimensions: technology in concentration of automation/information and transformation, service purpose, service authority, and delivery [36]. This would be highly considered as prioritization of concern due to (1) the complexity of citizen as the sources of 
key consideration for developing citizen centricity, (2) citizen would be a direct beneficiary, and (3) they would be the key participants and responsible for development [37].

More importantly, the key architecture designed of e-government would emphasize the level of participation, which is called e-participation and become one of the key focuses of the maturity level of government transformation into digitalization where the United Nations has the measurement survey frequently. The commonality definition of e-participation defined by the United Nations is to propose the process of engaging citizens through Information and Communication Technology in policy, decision-making, and service design and delivery so as to make it participatory, inclusive, and deliberative [38]. This also means the fundamental functions of e-participation would incorporate four dimensions, which are (1) e-services; informative or program announcement over internet, (2) e-democracy; participation in decision-making process via electronic channels, (3) e-commerce; all proposed public services to citizens such as tax paying, vehicle registration, exchange service, recreational programs also including government procurement process, (4) e-management; government internal improvement process [39]. Conceptually, e-participation has widely architected the propose solution having two possible alternative ways to engage with the citizen which are top-down engagement from government or bottom-up engagement by citizen whereby the proposed e-participation ontology was exercised [40].

An alternative view of architecting the e-participation suite, the government may consider the capability enablement the services into three kinds of participation engagements, which are one-way communication from government to citizen for information announcement, interactive two-way communication in the mode of consultation or response of any feedback, and the third is to encourage citizens to actively participate for deep engagement, whereby a citizen may participate in responding the request of defining or sharping the policies for instance [41,42].

\subsection{Fundamental of Research Methodology}

The proposed exercise for this research methodology is shown in Figure 2.
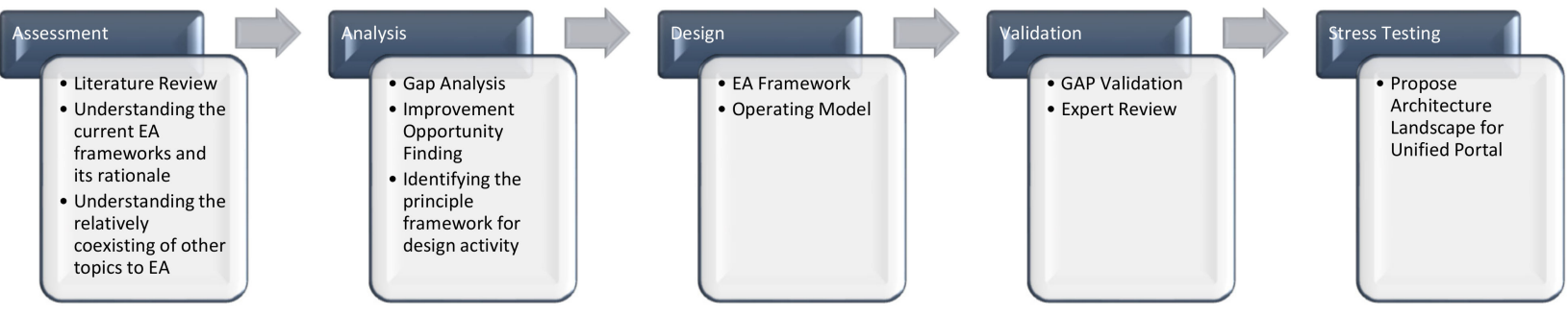

Figure 2. Research Methodology.

There are five exercise steps that would be the research guideline. Each step and its findings are described below.

1. Assessment. This step is to understand on availability of the frameworks (enterprise architecture framework or interoperability framework), co-relation of frameworks under multidisciplinary, origination of country specific frameworks, and its enforcement and the adoption capability of the e-government initiatives. Additionally, the review also seeks for some challenges or barriers that would impact the success of framework adoptable. Hence, the ultimate goal of this is to potentially find an opportunity of improvement in the framework context for more sustainable information technology landscape in terms of better cost control, better collaboration under the same standardization, and better resources consumption by sharable services.

The review topics that would be the key interested of this research and findings are described in Table 3. 
Table 3. Review Findings.

\begin{tabular}{c}
\hline Review Topic \\
\hline Fundamental need of achievable in \\
information technology improvement
\end{tabular}

Enterprise Architecture and Enterprise Architecture Framework

Enterprise Ontology and Alignment of Business to Information Technology

Enterprise Architecture and Interoperability Framework for e-Government

An Adoption of e-Government

e-Government Proposed Architecture

Objectives

To understand the key concentration requirement or expectation of information technology executive management have intended to achieve. Concentrate in the survey results of the relevant information technology executive management.

To validate the principle of conceptualization of the enterprise architecture which are being standardized by ISO/IEC/IEEE. Review the deliverables of practical enterprise architecture frameworks like Zachman Framework for Enterprise Architecture (ZFEA), The Open Group Architecture Framework (TOGAF), Gartner Enterprise Architecture Framework (GEAF), and specific enterprise architecture frameworks likes Federal Enterprise Arhcitecture (FEA)which concentrated serving the public sector or suitable for national governments.

To explore the means of enterprise ontology and the importance of alignment needed in between business and information technology in principle. Realize the meaning of linkage of those to enterprise architecture.

To understand the key role of interoperability on enterprise architecture frameworks in order to enable the information sharing in between the inter-government agencies and public.

To seek the overall outcome of deployment of the e-Government by understanding the success factors and challenges facing.

To understand on availability of e-government proposed architecture and implementation rationale in order to analyze the detail architecture, its advantages and benefits and challenges

for identifying opportunity of improvement.
Findings

By the survey with information technology executive management, the key concentration of their expectation has identified to the efficiency of cost control, better collaboration with business and organization strategy, and improving the quality of service.

Basically, the practical enterprise architecture frameworks have proposed the framework in concentration within the core process as per described by

Figure 1. The challenge would be the clarity guidance or governance and strategic direction of driving the framework, which the government would expect to clearly define.

Additionally, the analysis finding by systematic literature review has shown that there are a limited number of researches paid attention on adaption of enterprise architecture framework and its challenges, especially on the group of developing countries.

Theoretically, an enterprise ontology has described the entity, relationship of the entity, role, actor, and state with its activities and processes also

incorporating the impact of organization, strategy, and marketing, which would be considered as mandated of

successfulness enterprise architecture to collaborate with enterprise ontology.

There are implemented clarity legislation of enterprise architecture framework by also incorporating the principal of interoperability into the framework specifically for developed countries.

Developing countries have fragmented guidance of interoperability and enterprise architecture framework, which lead to challenges of sustainable information technology landscape. Important to successful enabling the e-government initiative, standardization, policy, and governance must be taken into consideration for fundamentally mandated the architecture context.

Key consideration of architecting the e-government is to concern on firstly the national data model, whereby all government agencies would be able to leverage, and secondly the concern on e-participation, whereby the conceptual of having full participation of citizens under the national strategy and plan. 
2. Analysis. The step of analysis is to study on any availability survey results that link to the expectation of effective outcome of adapting enterprise architecture framework into national government and their agencies at the comprehensive and holistic viewpoint. Hence, the goal of this analysis is to identify the level of intensity of each survey expectation against the existing practicality enterprise architecture framework. The concentration analysis for this paper would be focused on ZFEA and TOGAF as per identifiable at the most referral for both the private and public sector. By doing this, the analysis result would expect to lead the opportunity of proposing the sustainable enterprise framework for government specifically for developing countries.

The step of analysis has begun with the understanding of organization expectation on exercising the enterprise architecture followed by validating the proposed deliverables of each enterprise architecture framework for adoptability over the government organizations.

\section{Step 1-Understandable of Organization Expectation}

In the survey results of expectation on deliverable contribution of enterprise architecture and interoperability for e-government conducted by Janssen [3] with a group of line management, decision maker and enterprise architect for government agencies have demonstrated three kinds of expectation being concerned (desired goals, desired enterprise architecture products, and desired governance). Table 4 has described the analysis finding of expectations as mentioned above.

Table 4. Janssen's Survey Result.

\begin{tabular}{|c|c|c|}
\hline Survey Expectation & As-is & Expected \\
\hline \multicolumn{3}{|l|}{ Desired Goals } \\
\hline Interoperability & $\mathrm{H}$ & $\mathrm{H}$ \\
\hline Client-Orientation & $\mathrm{H}$ & $\mathrm{H}$ \\
\hline Enabling Reuse & M & $\mathrm{H}$ \\
\hline Flexibility and Agility & M & $\mathrm{H}$ \\
\hline Coherency & $\mathrm{M}$ & $S$ \\
\hline Aligning IT and Business & $\mathrm{L}$ & $\mathrm{SH}$ \\
\hline Decision Making & $\mathrm{L}$ & $\mathrm{SH}$ \\
\hline Enabling Transformation & $\mathrm{L}$ & $\mathrm{SH}$ \\
\hline \multicolumn{3}{|l|}{ Desired Enterprise Architecture Products } \\
\hline Framework & $\mathrm{H}$ & $\mathrm{H}$ \\
\hline Principals and Policies & $\mathrm{H}$ & $\mathrm{H}$ \\
\hline Patterns & $\mathrm{H}$ & $\mathrm{H}$ \\
\hline Tools & $\mathrm{L}$ & $\mathrm{H}$ \\
\hline Basic Facilities & $\mathrm{L}$ & $\mathrm{H}$ \\
\hline Shared Services & $\mathrm{L}$ & $\mathrm{SH}$ \\
\hline \multicolumn{3}{|l|}{ Desired Governance } \\
\hline Decision Making Structure and Support & $\mathrm{L}$ & $\mathrm{SH}$ \\
\hline Alignment Process ensuring Involvement & $\mathrm{L}$ & $\mathrm{SH}$ \\
\hline Formal Communication to enable knowledge distribution & $\mathrm{L}$ & $\mathrm{SH}$ \\
\hline
\end{tabular}

As-is (H: High Contribution, M: Medium Contribution, L: Low Contribution); Expected (H: Higher than As-is, S: Same as As-is, SH: Significantly Higher than As-is).

The opportunity of proposed sustainable government enterprise architecture framework supporting the national government would be concentrated in considering shared services and governance concerns being the framework component. Ultimately, this pro- 
posed will also incorporate the need of flexibility and agility as well as being the better source of decision making which this expectation also being mentioned by Lapalme et al. [43].

Step 2-Validating the Selected Enterprise Architecture Framework

The summary below has described the lists of required maturity factor by each of literature review exercise shown in Table 5.

The summary of this exercise has demonstrated that there are lists of required maturity factors being significantly impacted by the success of exercise on government enterprise architecture using the practical enterprise architecture framework. The figure below has described the highly frequently mentioned required maturity factor relevant with government enterprise architecture framework shown in Figure 3.

Table 5. Lists of Required Maturing Factor by Literature Review.

\section{Components Mentioned}

\begin{tabular}{|c|c|c|c|c|c|c|c|c|c|c|c|c|c|c|c|}
\hline 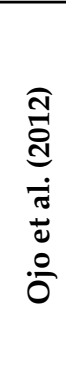 & 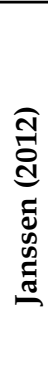 & 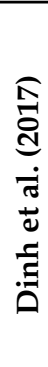 & 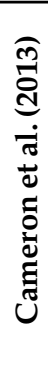 & 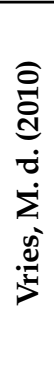 & 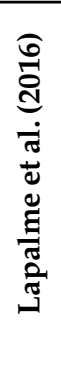 & 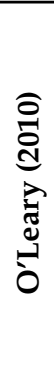 & 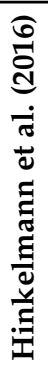 & 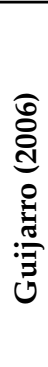 & 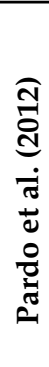 & 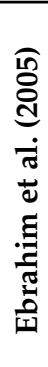 & 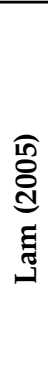 & 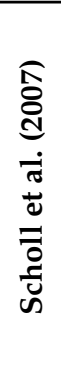 & 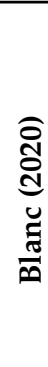 & 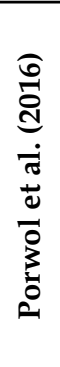 & 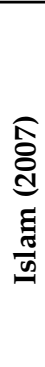 \\
\hline
\end{tabular}

\footnotetext{
Management Support \&

Involvement

Business Participation (Business

Alignment)

Governance Structure

Legislation (Compliance)

Skills Development

EA Policies \& Processes

External Support (Consultant)

Change Management

Functional Knowledge \&

Processes

Communication \& Adoption

Resources (Organization \& Roles)

Clear Vision \& Goal (Strategic

Alignment)

Marketing

Funding

Interoperability

Sharable Services \& Collaboration

Standard

Taxonomy

Reference Model

Integration

Government Data Catalog

Citizen Centric Data Model

Technology \& Security

e-Participation
}

\section{$x$}

$\mathrm{x} \quad \mathrm{x} \quad \mathrm{x}$

$\begin{array}{lllll}x & x & x & x\end{array}$

$x \quad x \quad x$

$x \quad x$

$\mathrm{x} \quad \mathrm{x}$

$x$

$\mathrm{X}$

$\mathrm{x}$

$x \quad x$

$\mathrm{x}$

$\mathrm{x}$

$$
\mathrm{x} \quad \mathrm{x}
$$

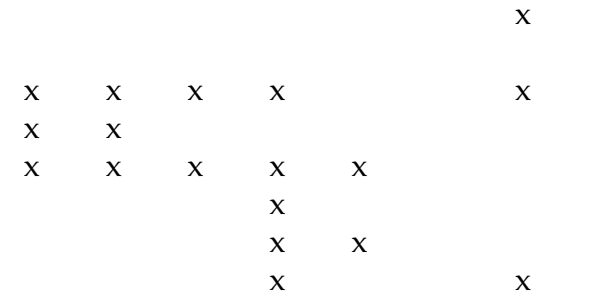

$\mathrm{X}$

$x$

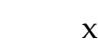

$\mathrm{x}$

$\mathrm{x}$

$\mathrm{X}$
$\mathrm{x}$
x $\quad x \quad x$ $\begin{array}{llllll}x & x & x & x & x\end{array}$

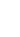

$\begin{array}{lll}x & x\end{array}$

$\begin{array}{lllll}x & x & x & x & x\end{array}$

x $\quad \mathrm{x}$

$\mathrm{x}$

$\mathrm{X}$ $\begin{array}{lll}x & x & x \\ x & x & x\end{array}$

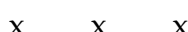

$\mathrm{X}$

$\mathrm{X}$

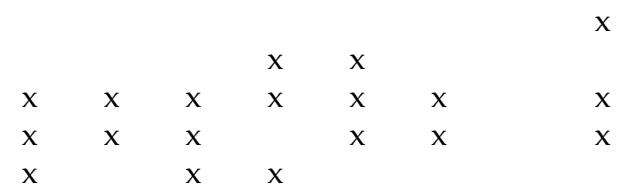




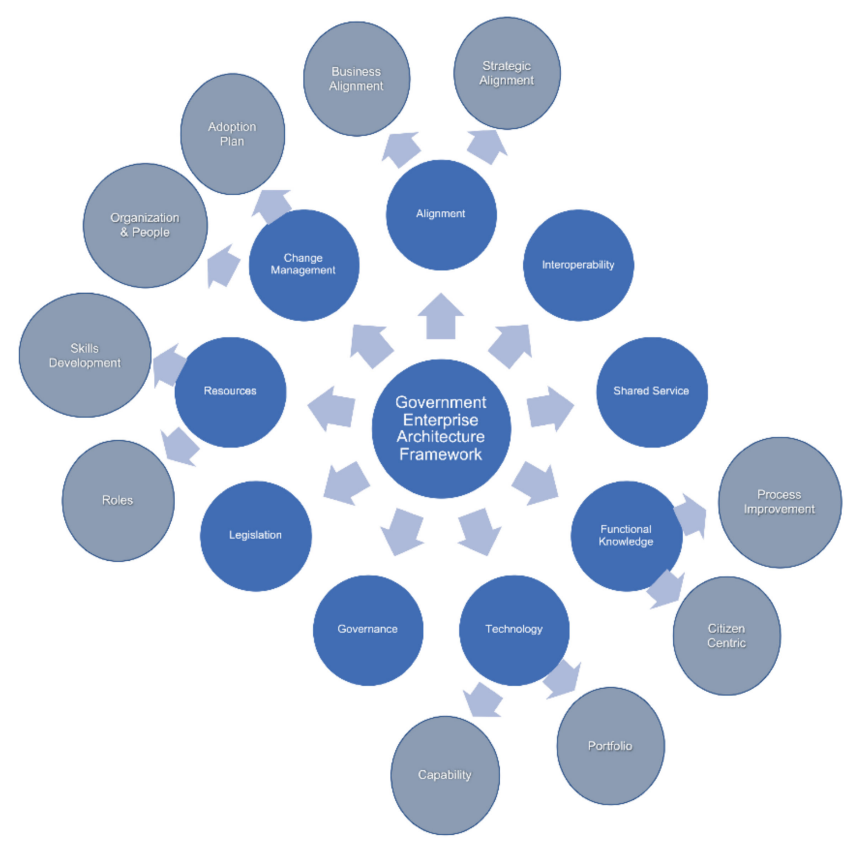

Figure 3. Relevant Required Maturing Factors.

The validation method was designed using the scoring of 0 where the capability does not exist, 1 where the capability does exist, and 0.5 where the capability partially exists with the proposed of weight scores for a critical level of government required fundamentally. The rationale of designing the weight score has been based on the e-Government/eParticipation description in Section 2.6, whereby several developing countries have faced some challenges in order to strategically manage the transformation program by centralized cascading with proper collaboration and sharable for cross-government agencies.

The validation finding in Table 6 has demonstrated that those selected enterprise architecture frameworks having less concentration (40 scores out of 100 for ZEAF and 50 scores out of 100 for TOGAF) in government adoption while those frameworks have demonstrated accomplishment widely in the private sectors which those frameworks would be well recognized. In this regard, the most significantly higher expectation has been motivated researcher to comprehensively consider the possibility of an enhancement of the enterprise architecture framework for government in general concentrating on the group of developing countries by having explicitly described the framework execution guidance for more clarity and understandability.

Table 6. Validation Exercise Capability for Government.

\begin{tabular}{|c|c|c|c|c|c|}
\hline \multirow[b]{2}{*}{ Key Validation Topics } & \multirow[b]{2}{*}{$\%$ Weight } & \multicolumn{2}{|c|}{ ZFEA } & \multicolumn{2}{|c|}{ TOGAF } \\
\hline & & $\begin{array}{l}\text { Existing } \\
\text { Score }\end{array}$ & $\begin{array}{c}\text { Weight } \\
\text { Score }\end{array}$ & $\begin{array}{l}\text { Existing } \\
\text { Score }\end{array}$ & $\begin{array}{c}\text { Weight } \\
\text { Score }\end{array}$ \\
\hline 1. Alignment IT and Business/Participation in Business Exercise & 10 & 0.5 & 5 & 0.5 & 5 \\
\hline 2. Decision Making/Legislation Impact and Support & 10 & 0 & 0 & 0 & 0 \\
\hline $\begin{array}{l}\text { 3. Enabling Transformation/National Transformation } \\
\text { Cascading/Top-Down Architecture }\end{array}$ & 15 & 0.5 & 7.5 & 0.5 & 7.5 \\
\hline 4. Promoting Shared Services Capability & 10 & 0 & 0 & 0 & 0 \\
\hline 5. Emphasis in Architecture Exercise Governance & 5 & 0 & 0 & 0.5 & 2.5 \\
\hline 6. Emphasis in Interoperability & 5 & 0.5 & 2.5 & 1 & 5 \\
\hline $\begin{array}{l}\text { 7. Emphasis in Operational Process Improvement during } \\
\text { the Architecture Exercise }\end{array}$ & 10 & 0.5 & 5 & 1 & 10 \\
\hline $\begin{array}{l}\text { 8. Emphasis in Analysis of Gap, Impact, and Dependency during } \\
\text { the Architecture Exercise }\end{array}$ & 5 & 1 & 5 & 1 & 5 \\
\hline 9. Emphasis in Information Policy & 15 & 1 & 15 & 1 & 15 \\
\hline 10. Emphasis in Cross-Organization Collaboration & 15 & 0 & 0 & 0 & 0 \\
\hline Total Scores & 100 & & 40.0 & & 50.0 \\
\hline
\end{tabular}


3. Design. The main activity of this step is to identify the theoretical baseline framework to be the design fundamental which the Supply-Chain Operations Reference (SCOR) will be used as the baseline structure of the design context of the sustainable government enterprise architecture framework. In principle, SCOR has declared the exercise steps to be four stages, which are Plan, Source, Make, and Deliver. Basically, this model would be able to apply as one of the best-in-class with practical management and having clarity in four levels of exercise method starting from identify broad definitions under the four stages of SCOR dimensions (Plan, Source, Make, and Deliver), identifying core process categories under those four stages, define the execution method of those core processes in detail, finally implementing those designs as shown in Figure 4 [44].

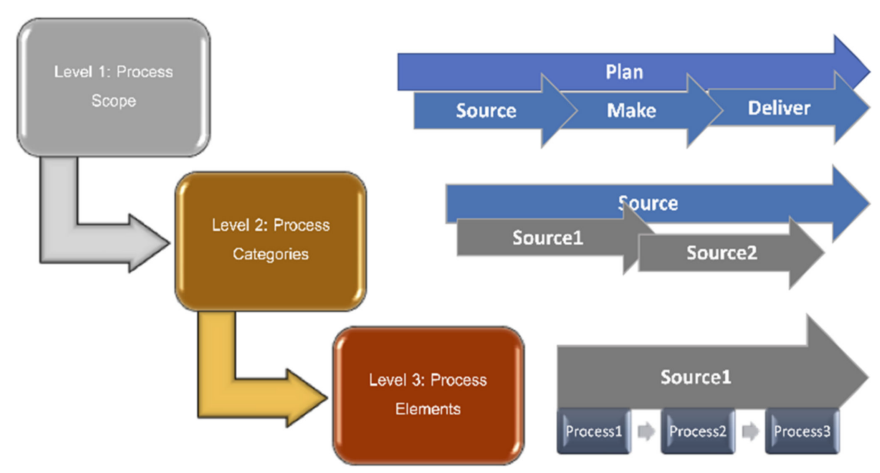

Figure 4. Supply-chain Operations Reference Model Structure.

Additionally, the basic principle of SCOR was fundamentally designed to be mainly suited with the manufacturing process, beginning with the planning stage and delivering the product result at the end stage, thus holistically realizing the enablement result of enterprise architecture framework exercise under the SCOR methods and being able to properly propose the appropriate improvement further. The additional Evaluate step as described in Figure 5 has been proposed as enhanced SCOR to apply over the original SCOR process which is to mainly recognize the outcome efficiency as per designated of measurable method likes the total return ratio, total spending for instance.

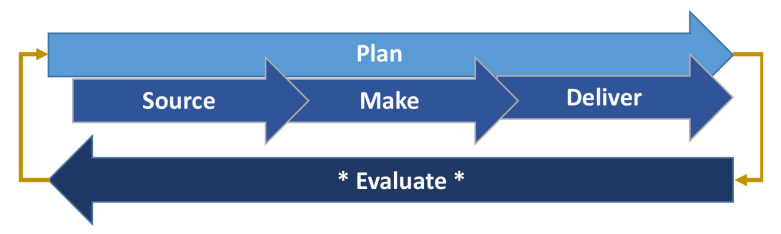

Figure 5. Enhanced Supply-Chain Operations Reference (SCOR).

4. Validation. The validation exercise has proposed having two activities, which are (1) validating capability of the proposed framework same as validation criteria that exercise over ZEAF and TOGAF, which analysis findings has described in the Analysis step, and (2) conducting an interview session with a predefined list of questionnaires for field expertise to respond with their satisfaction level on the propose of sustainable government enterprise architecture framework.

The plan for conducting an interview is to identify the list of field expertise who have direct experience on heading the function of enterprise architecture or related function, whereby experiencing adoption of enterprise architecture framework for government in whole or partial. Thereafter, the exercise would submit the brief proposal in containing the descriptive of this research objective, motivation, literature review in literature categories, research method, and propose sustainable government enterprise architecture framework with the list of questionnaires using the satisfaction and agreement level from "not agree" or scoring as 1 to "strongly agree" or scoring as 5. After collecting all interview 
responses, the analysis finding would be proceeded by firstly calculating mean score using Equation (1) of each questionnaire item in order to realize the agreeable proposed framework components relevant with government perspective. Secondly, the acknowledged score findings is found by calculating the mean score of all inputs and the expectation of acceptable score of satisfaction level should not be less than 4.25 or 85 percentage of overall score.

$$
\text { Mean }(\mu)=\frac{1}{n} \sum_{i=1}^{n} a_{i}=\frac{a_{1}+a_{2}+a_{3}+\cdots+a_{n}}{n}
$$

Symbolic description, $\mathrm{n}$ means the total number of observations set of data where $a_{1}+a_{2}+a_{3}+\cdots+a_{n}$ representing the observations set of data.

Additionally, before making the score findings, the experiment has proposed to prove the index of dispersion [45] or variance-to-mean ratio (VMR) described in Equation (2) in order to realize the level of dispersion of the probability distribution over the set of observation data using variance Equation (3), which the VMR result would expect to be equal to 0 (not dispersed) or the minimal value in between 0 and 1 (under-dispersed). This means the given questionnaire score by all interviewees were consented.

$$
\begin{gathered}
\text { VMR }=\frac{\delta^{2}}{\mu} \\
\text { Variance }(\delta)=\frac{1}{n-1} \sum_{i=1}^{n}\left(a_{i}-\mu\right)^{2}
\end{gathered}
$$

5. Stress Testing. The testing step is planned to simulate the adaptation of sustainable government enterprise architecture framework by proposing the case study of Thailand for the proposed architecture landscape for one government agency that would be able to consolidate into the unified portal public services, which would be able to accommodate the definition of e-participation defining by the United Nations [46] and citizen centricity [34].

\subsection{The Sustainable Government Enterprise Architecture Framework}

The purpose of sustainable government enterprise architecture framework has been fundamentally designed based upon the enhanced SCOR as the previous section mentioned. Figure 6 has described the key components of sustainable government enterprise architecture framework.

There are 10 groups of activity under the fundamental SCOR process; plan, source, make, and deliver with an extended process; evaluate to be proposed as the enterprise architecture framework serving the architecture exercise for government and its agencies. The detailed explanation of each group is available in the following passages. 


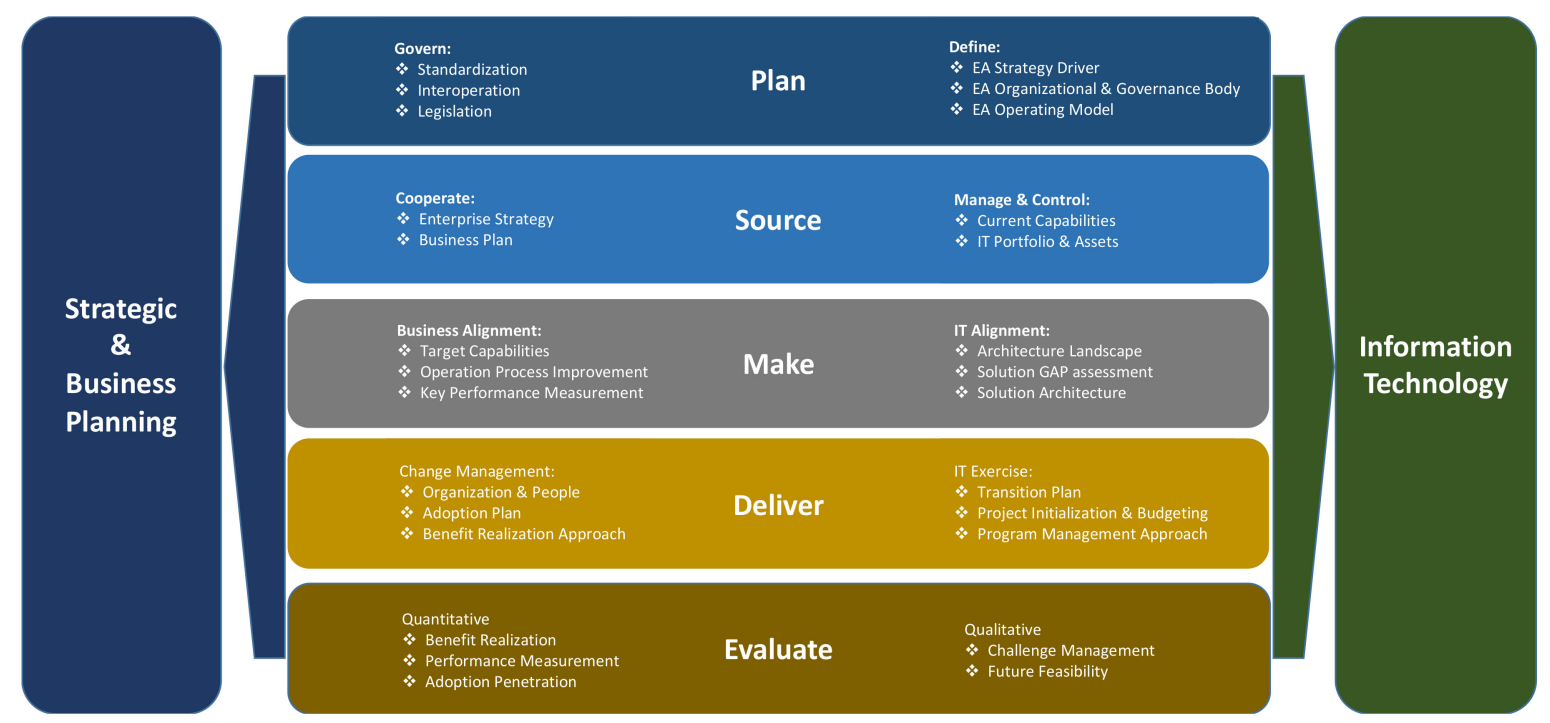

Figure 6. Sustainable Government Enterprise Architecture Framework.

\subsubsection{Plan}

This is the beginning exercise step of establishing the enterprise architecture initiative for government. As per the rapid change in the expectation of service capabilities, a variety of political commitments and modernization of technology evolution, the establishment of enterprise architecture, and its implementation of the framework must be taken into account as the permanently facilitated all relevant activities as the general function. Hence, this step is to fundamentally exercise for initialization of all required principles of further execution of information technology transformation under properly govern and steer as described in Figure 7.

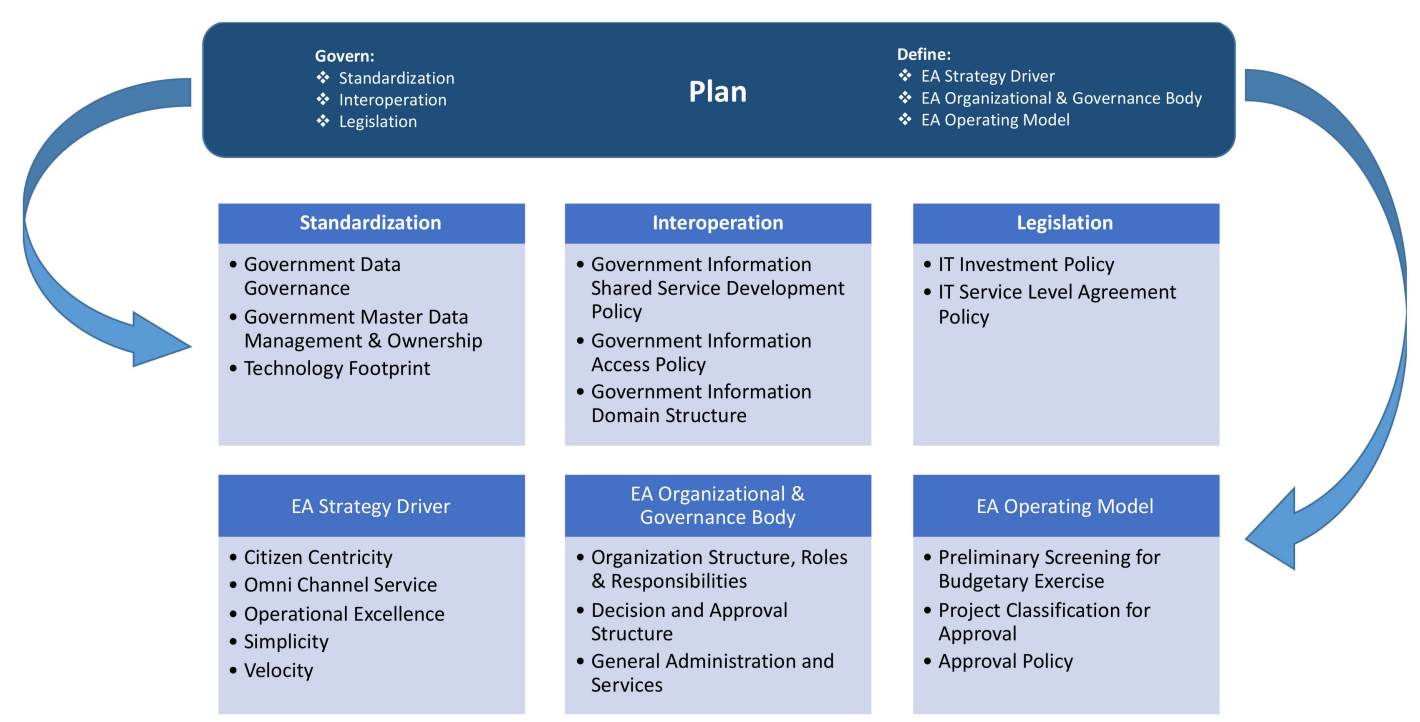

Figure 7. Detail Process of Plan Step.

\section{Govern}

The step of govern is to fundamentally provide commonality agreement that would be applied for government and all of its agencies in order to ensure that there are mandatory requirements for further collaboration and achieving the goal in between the interorganization of the government and its agencies. One important step is to address necessarily required legislation in order to eliminate unnecessarily traditional bureaucratic, as well as the "Silo" operational management, which would be the key barrier of achieving the goal. 


\section{Define}

This group of the process was designed for proposing the fundamental logistic activities of an establishment the enterprise architecture organization with clarity on roles and responsibilities as described in Figure 8 for example. Also, the strategic driver of enterprise architecture execution for the clarity outcome needs to be incorporated while establishment of this function has been defined.

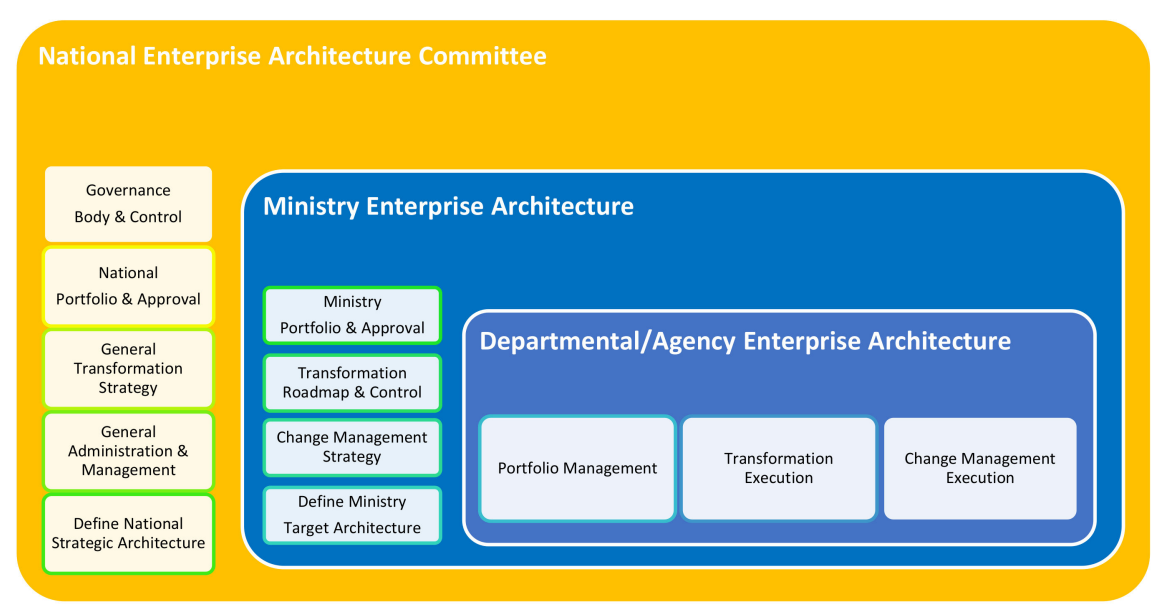

Figure 8. Sample Enterprise Architecture Organization, Roles, and Responsibilities.

\subsubsection{Source}

The source process is to ensure that all relevant information supporting continuously of enterprise architecture working protocol will be satisfactorily available with appropriate updating cycle.

\section{Cooperate}

The mean of this process is to significantly encourage the collaboration exercise on identifying strategic and business planning by having enterprise architecture team members who are competent on business strategic or business planning participating into the exercise of designing those plans deliverable, which would consider this function to be part of enterprise architecture in coordinating deep exercise with business strategy unit. The key benefit of having this responsibility being part of enterprise architecture would be preventing the loss of understanding on the expectation of business strategy as well as business planning when translating those plans to be the target capabilities or business architecture, the proposed business process improvement, or identifying key measurable of each capability initiative.

\section{Manage and Control}

This proposed step is to encourage enterprise architecture taking owned responsibility managing the information technology portfolio and controlling information technology assets. Thus, the key importance of this process is to propose the detailed operating procedure of information technology management in order to efficiently manage the information technology portfolio to be updated and aligned with availability of information service solutions and defining the effective management and control the status of information technology inventory assets covering all components of hardware and software. This would be utilized as the fundamental support information for future investment or enhancement on information technology solution.

\subsubsection{Make}

This Make process would need to practically begin with the "Bird-eye" view exercise, then drilling the relevant architecture contents down to the execution layer which mean the overall transformation strategy of government would be harmoniously aligned to 
the operational agencies. Additionally, this process also proposes the clarity guidance of improving the operation process of public services function whereby the "e-"capabilities like e-verification, e-document for instance and robotic automation process, have been considered for adaptation as key success factors of achieving the goal of transformation. As per the proposed activities, there are several steps that should be taken into the exercise which would be efficiently managed and executed. Figure 9 has described the rationale of detailed exercise steps of this process which has proposed the exercise activities covering both of business and information technology with below detail description.

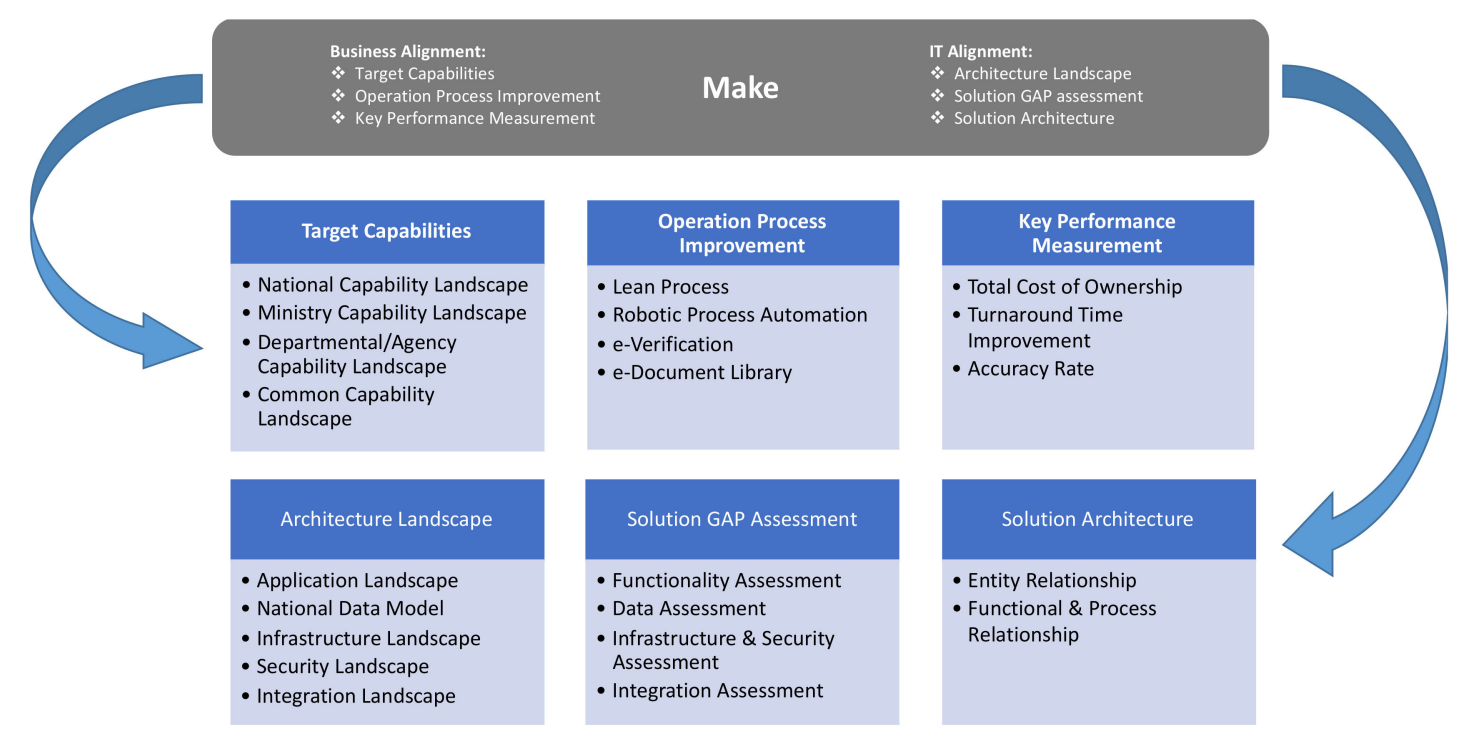

Figure 9. Detailed Process of Make Step.

\section{Business Alignment}

The business alignment step has significantly proposed of enterprise architecture to perform an interpretation of government strategy contexts which would be the national strategic planning, national development planning, or government public commitment to architecture capabilities and the interrelationship of those capabilities as the strategic target. Ultimately, the mean of capability will describe the kind of public and administrative services that a citizen would be able to utilize in any available channels under commonality experience. Importantly, this step ensures the cascading of architecture capability has seamlessly distributed to all responsible units, whereas the commonality capability would be streamlined and consolidated into common capability and managed separately by a centralized unit.

Criticality, the end stage of this process exercise ensures all proposed capability will be measured as the performance outcomes. Thus, the framework would propose including the design of key performance measurement of each improvement capability, whereby the key concentration of improvement could be the total cost of ownership or total turnaround time of citizen service, for instance.

\section{IT Alignment}

The importance of Information Technology alignment exercise is to ensure that there is a comprehensive interpretation of the mean of all required target capabilities as described in business alignment session to the description of information technology landscapes in several domain areas and performing the gap analysis of available components in order to potentially identify leveraging opportunity. The final step of this process is to design the solution architecture of each agency office. There are two critical keys of defining the architecture landscape for national perspective, which are (1) national data model in the description of citizen-centricity approach and (2) integration landscape in the description of sharable and openable under properly managed and control. 


\subsubsection{Deliver}

Deliver process is considered as the step that required all logistic supporting further implementation of proposed target architecture which could be completely or partially deliverable of the target architecture depending on possibility of that implementation capability. But more importantly, the plan of deployment would need to consider any possibility impact to the success of that deployment. Meanwhile, the delivery process would need to be effectively managed and planned for future activity.

\section{Change Management}

The change management has been proposed to be part of the delivery process for the activities that need to plan for handling the delivery of new capability into the ecosystem for serving the public services in efficient preparation and execution. This framework has proposed three major activities which are (1) properly managing organization and people, (2) efficiently defining the adoption plan, and (3) defining the benefit realization approach to be effectively measurable.

\section{IT Exercise}

This process in concentration with information technology is to exercise on information service solution enablement accommodating the strategic plan of enterprise architecture that is being defined as the target architecture in the Make process. This process would begin after the target capability of some specific public service has been prioritized to implement. Then, the following steps should be exercised, which are (1) smoothly defining the transition plan of promoting new capability into the ecosystem, (2) properly definingthe project prioritization and budgeting suiting with strategic plan, and (3) defining the program management approach to steer and manage the project execution effectively.

\subsubsection{Evaluate}

The expectation of this process is to measure for better understandability on the efficiency of releasing the new or enhancing public services to citizens by concentrating on both quantitative and qualitative realization for further finding and improvement in the case of evolution or advance innovation being considered for more suitable adoption. Or, the result of measuring should be transitioned to be a new baseline of releasing other target architecture or new public service with proper improvement.

\section{Quantitative}

The purpose of quantitative measurable is to recognize the overall outcome response of deliverable for both of business realization and information technology performance referring to the measurements target designing upon prior process of the framework. The fundamental measurement objective has defined for comparison before and after on the efficiency of government strategy and planning as well as the appreciation of public response. At minimum of enterprise architecture involvement, the following measurements should be actively concerned.

- Business Realization.

- Penetration rate of citizen cooperation,

- Government resources efficiency and productivity,

- Operation cost reduction,

- Improvement ratio of specific campaign like safety ratio.

- Information Technology.

- Total cost of ownership of Information Technology Investment,

- Service turnaround times,

- Accuracy rate improvement. 


\section{Qualitative}

The qualitative approach is to realize the challenges facing upon execution of new architecture or new solution starting at the point of initiation up until the release to public stage. This activity has intended to gather all challenges facing, understanding the root cause of challenges, and finding the resolution for further improvement. Additionally, this stage also suggests further research and feasibility study for future improvement.

In the principal of exercising an enterprise, architecture has targeted to achieve the improvement expectation on people, process, and technology; the government perspective is also targeted the same way. Thus, the evaluated result would be expected to be utilized for that improvement, especially the renovation of government service to public to be digitalization.

\section{Discussion}

In the description of fundamental of research methodology, the validation process after getting the first draft of proposed a sustainable government enterprise architecture framework was designed into two activities, which are (1) validating capability of the proposed framework same as validation criteria that exercise over ZEAF and TOGAF which analysis findings have described in Analysis step, and (2) conducting an interview session with a predefined list of questionnaires for field expertise to response their satisfaction level. This section is to describe the results of those validation exercises on the following.

\subsection{Validating the Capability of Proposed Framework}

Referring to the analysis of capability score in Section 2, Table 7 has shown the comparison of capability score over the proposed sustainable government enterprise architecture framework that the framework designed has emphasized on the transformable traditional operation procedures such as isolated architecture, struggle with legal policy to be more integrated architecture with appropriately legal support as well as promoting the strategic alignment in the view of nation-wide cascading and improving operation processes.

Table 7. Validating Capabilities of Proposed Framework.

\begin{tabular}{|c|c|c|c|c|c|c|c|}
\hline \multirow[t]{2}{*}{ Key Validation Topics } & \multirow[t]{2}{*}{ \% Weight } & \multicolumn{2}{|c|}{ ZFEA } & \multicolumn{2}{|c|}{ TOGAF } & \multicolumn{2}{|c|}{$\begin{array}{c}\text { Sustainable Government } \\
\text { Enterprise Architecture } \\
\text { Framework }\end{array}$} \\
\hline & & $\begin{array}{l}\text { Capability } \\
\text { Score }\end{array}$ & $\begin{array}{l}\text { Weight } \\
\text { Score }\end{array}$ & $\begin{array}{l}\text { Capability } \\
\text { Score }\end{array}$ & $\begin{array}{l}\text { Weight } \\
\text { Score }\end{array}$ & $\begin{array}{l}\text { Capability } \\
\text { Score }\end{array}$ & $\begin{array}{l}\text { Weight } \\
\text { Score }\end{array}$ \\
\hline $\begin{array}{l}\text { 1. Alignment IT and } \\
\text { Business/Participation in } \\
\text { Business Exercise }\end{array}$ & 10 & 0.5 & 5 & 0.5 & 5 & 1 & 10 \\
\hline $\begin{array}{l}\text { 2. Decision Making/Legislation } \\
\text { Impact and Support }\end{array}$ & 10 & 0 & 0 & 0 & 0 & 1 & 10 \\
\hline $\begin{array}{l}\text { 3. Enabling Transformation/ } \\
\text { National Transformation } \\
\text { Cascading/Top-Down } \\
\text { Architecture }\end{array}$ & 15 & 0.5 & 7.5 & 0.5 & 7.5 & 1 & 15 \\
\hline $\begin{array}{l}\text { 4. Promoting Shared Services } \\
\text { Capability }\end{array}$ & 10 & 0 & 0 & 0 & 0 & 1 & 10 \\
\hline $\begin{array}{l}\text { 5. Emphasis in Architecture } \\
\text { Exercise Governance }\end{array}$ & 5 & 0 & 0 & 0.5 & 2.5 & 1 & 5 \\
\hline $\begin{array}{l}\text { 6. Emphasis in Interoperability } \\
\text { 7. Emphasis in Operational }\end{array}$ & 5 & 0.5 & 2.5 & 1 & 5 & 1 & 5 \\
\hline $\begin{array}{l}\text { Process Improvement during } \\
\text { the Architecture Exercise }\end{array}$ & 10 & 0.5 & 5 & 1 & 10 & 1 & 10 \\
\hline
\end{tabular}


Table 7. Cont

\begin{tabular}{|c|c|c|c|c|c|c|c|}
\hline \multirow[t]{2}{*}{ Key Validation Topics } & \multirow[t]{2}{*}{$\%$ Weight } & \multicolumn{2}{|c|}{ ZFEA } & \multicolumn{2}{|c|}{ TOGAF } & \multicolumn{2}{|c|}{$\begin{array}{c}\text { Sustainable Government } \\
\text { Enterprise Architecture } \\
\text { Framework }\end{array}$} \\
\hline & & $\begin{array}{l}\text { Capability } \\
\text { Score }\end{array}$ & $\begin{array}{l}\text { Weight } \\
\text { Score }\end{array}$ & $\begin{array}{l}\text { Capability } \\
\text { Score }\end{array}$ & $\begin{array}{l}\text { Weight } \\
\text { Score }\end{array}$ & $\begin{array}{l}\text { Capability } \\
\text { Score }\end{array}$ & $\begin{array}{l}\text { Weight } \\
\text { Score }\end{array}$ \\
\hline $\begin{array}{l}\text { 8. Emphasis in Analysis of Gap, } \\
\text { Impact, and Dependency during } \\
\text { the Architecture Exercise }\end{array}$ & 5 & 1 & 5 & 1 & 5 & 1 & 5 \\
\hline 9. Emphasis in Information Policy & 15 & 1 & 15 & 1 & 15 & 1 & 15 \\
\hline $\begin{array}{l}\text { 10. Emphasis in } \\
\text { Cross-Organization Collaboration }\end{array}$ & 15 & 0 & 0 & 0 & 0 & 1 & 15 \\
\hline Total Scores & 100 & & 40.0 & & 50.0 & & 100.0 \\
\hline
\end{tabular}

In the findings of validating the capabilities of the proposed sustainable government enterprise architecture framework, its capabilities have been designed accommodating the current challenges of cross-organization collaboration and national transformation strategy. Thus, all required capabilities were considered as key criticality of success in the intention of effectively drive the changes.

\subsection{Interview Responded and Discussions}

The activity would be conducted by having an interview session with five selected relevant representatives who have contributed their professional services to the organization both of private and public sector, which are three professionals in the private sector having an experience of enterprise architecture and two government officers who are responsible for transformation execution. The list of questionnaires has been submitted together with the brief of this article as described in a prior section and guide the score indicator by having proposed the range of agreeable score as per mentioned in Section 3.

The list of questionnaires has been designed based upon the key consideration of proposing the sustainable government enterprise architecture framework which emphasized five key areas that would create an inference of transformation consensus among all government agencies that required high collaboration in order to achieve their strategy alignment with the national target. The keywords of those questionnaires are (1) legislation support, (2) top-down target architecture, (3) architecture governance, (4) shared services, and (5) cross-organization collaboration, which the score finding has described in statistical information as shown in Figure 10.

In summary, the overall scores have demonstrated the consensus of the interviewees responded which the final mean value was 4.50 or equivalent to 90 percentage. The VMR is shown as under-dispersed, which supports the scores finding as mentioned.

In a nutshell, the proposed sustainable government enterprise architecture framework has been emphasized on how to comprehensively transform the national public service capabilities in the dimensions of collaboration, alignment, structural, sharable, and legal which the framework would be the suitable method for government or public sector to execute on target architecture improvement for accommodated national transformation like digitalization, promoting e-participation, e-government, or structuring the public service using citizen centricity by satisfying the constrained government way of working, like privacy law, for instance. Hence, the key highlight of propose of sustainable enterprise architecture for government has demonstrated the following capabilities. 


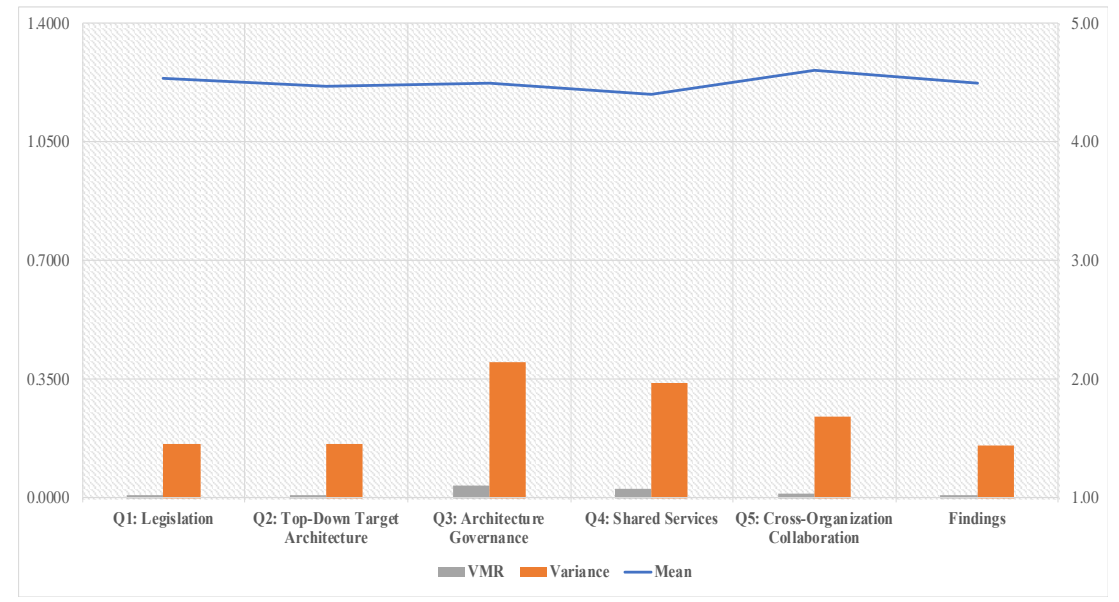

Figure 10. Questionnaires Response Findings.

1. Business strategy and target capabilities of business has clearly proposed the cascading structure from national strategy down to departmental or agency strategy.

2. Cross-organization collaboration will be the key driver of making the successfulness of target deliverable according to national strategy and target architecture cascading.

3. The architecture governance would be substantially improved to centralized overlook in order to comprehensively acknowledge all initiatives and transformation execution.

4. The fundamental legislation supporting comprehensively executed enterprise architecture proposed transformation roadmap has been emphasized at the plan process.

5. Clearly define national data model using the citizen centricity approach. Each agency should be able to leverage sharable services over the citizen centric model.

6. The proposed framework would be able to execute using an agile approach as there is no solid dependency of each process whereby the exercise would be partially executed according to partial readiness of each deliverable. More importantly, the core of the exercise over this framework is to ensure the strategy driver of national level must be explicitly defined and be able to further execute properly.

\subsection{Framework Exercise for Thailand's Land Transportation Case Study}

One of the most actively required citizen participations in a daily activity is the services of land transportation, which Thailand government has structured this majority services function under the Ministry of Transport. The key consideration of this proposed framework exercise is to concentrate in land transportation administrative services in relation with information technology whereby the service responsibility is managed by the Department of Land Transport.

The proposed exercise activities and defining the target architecture of transportation administration services would effectively adopt on sustainable government enterprise architecture framework following all required activities from the plan stage throughout the evaluate stage. In this case study, the proposed action taken of each framework stage will be described in the next sub-section, and the proposed of target architecture will be described in the last sub-section.

\subsubsection{The Findings of Strategic Actions}

Referring by the detail proposed of exercise on sustainable government enterprise architecture framework, the figures below have shown the findings of the criticality exercise over the framework adoption describing required activities of the Department of Land Transport for transformation adoption and plan.

Firstly, the strategy of enterprise architecture at the national level has been defined as the fundamental principle for all government offices and its agencies have been directed in order to transform their information system serving public services into the same standard 
and strategic direction. Figure 11 has described the key strategy of national enterpriswe architecture (National EA) having five dimensions, which directed all government offices and its agencies to exercise into the same expected target.

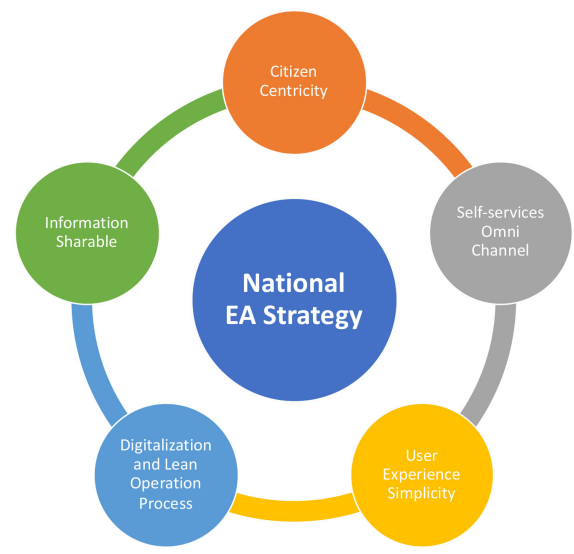

Figure 11. National EA Strategy.

Figure 12 has described the organization structure of enterprise architecture at the national perspective by including all required organizational layer.

\begin{tabular}{|c|c|c|}
\hline \multirow{14}{*}{$\begin{array}{l}\text { National EA } \\
\text { Organization \& } \\
\text { Governance } \\
\text { Body }\end{array}$} & \multirow{6}{*}{$\begin{array}{l}\text { National Enterprise } \\
\text { Architecture Committee }\end{array}$} & Taking the role of governance body and control, \\
\hline & & $\begin{array}{l}\text { Rationalized the operating model for entire enterprise architecture } \\
\text { organization down to agency level. }\end{array}$ \\
\hline & & $\begin{array}{l}\text { Managed and controlled information technology components of } \\
\text { national portfolio supporting sharable capability, }\end{array}$ \\
\hline & & $\begin{array}{l}\text { Defining national transformation strategy aligning with national } \\
\text { strategic planning, }\end{array}$ \\
\hline & & $\begin{array}{l}\text { Defining national target architecture covering public services } \\
\text { capability, national data model and technology }\end{array}$ \\
\hline & & $\begin{array}{l}\text { standardization, and } \\
\text { Performing as general administrative of its organization. }\end{array}$ \\
\hline & \multirow{4}{*}{$\begin{array}{l}\text { Ministry Enterprise Architecture } \\
\text { Committee }\end{array}$} & $\begin{array}{l}\text { Managed and controlled information technology components at the } \\
\text { ministry level, }\end{array}$ \\
\hline & & Defining ministry transformation roadmap, \\
\hline & & $\begin{array}{l}\text { Defining ministry target architecture aligning with national target } \\
\text { architecture, }\end{array}$ \\
\hline & & Defining change management strategy for citizen adoption. \\
\hline & \multirow{4}{*}{$\begin{array}{l}\text { Departmental or Agency } \\
\text { Enterprise Architecture } \\
\text { Committee }\end{array}$} & $\begin{array}{l}\text { Managed and controlled information technology components } \\
\text { specifically at their organization, }\end{array}$ \\
\hline & & $\begin{array}{l}\text { Defining organization target architecture aligning with ministry } \\
\text { transformation roadmap and target architecture, }\end{array}$ \\
\hline & & Executing the transformation plan, \\
\hline & & Executing change management plan supporting adoption. \\
\hline
\end{tabular}

Figure 12. National EA Organization and Governance Body.

Figure 13 has shown the key components of EA Governance that would consider as key critical success factors of driving the national enterprise architecture program in the goal of national transformation to fully digital enablement. 


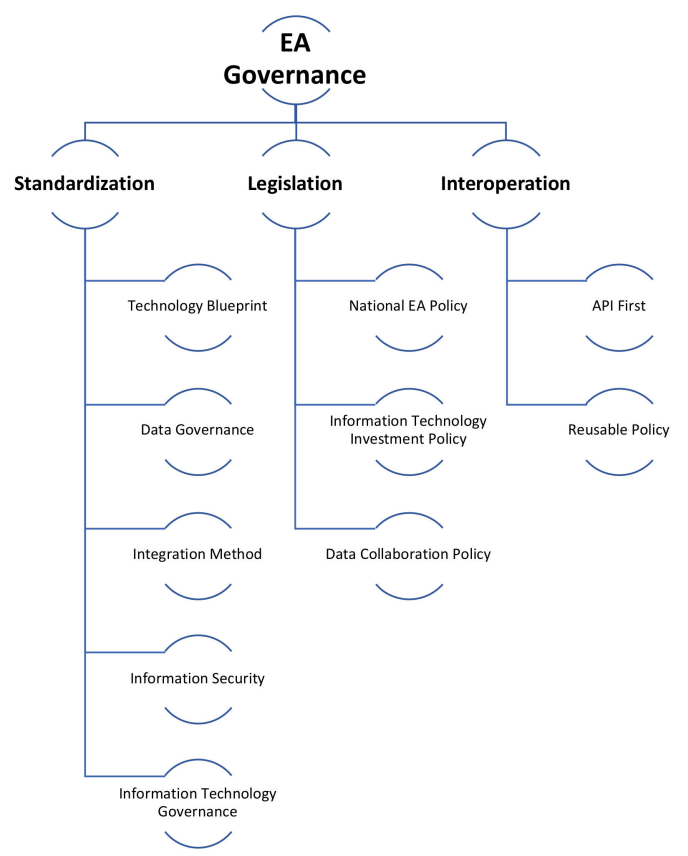

Figure 13. National EA Governance.

\subsubsection{The Findings of Target Deliverables}

This stage would be exercised upon the readiness of planning preparation as described in the previous section and the readiness of supporting information, which is described in the sourcing stage. Thus, the making stage would be concentrated in designing target capabilities of future stage of information services.

Figure 14 has demonstrated the comprehensive service capabilities of national services proposing to their citizen. This target would be considered as the baseline of further defining the ministry target capabilities in alignment with its national capabilities. Additionally, there will be the sharable layer being defined for centralized managing of all inter-department connectivity in the standardization procedures.

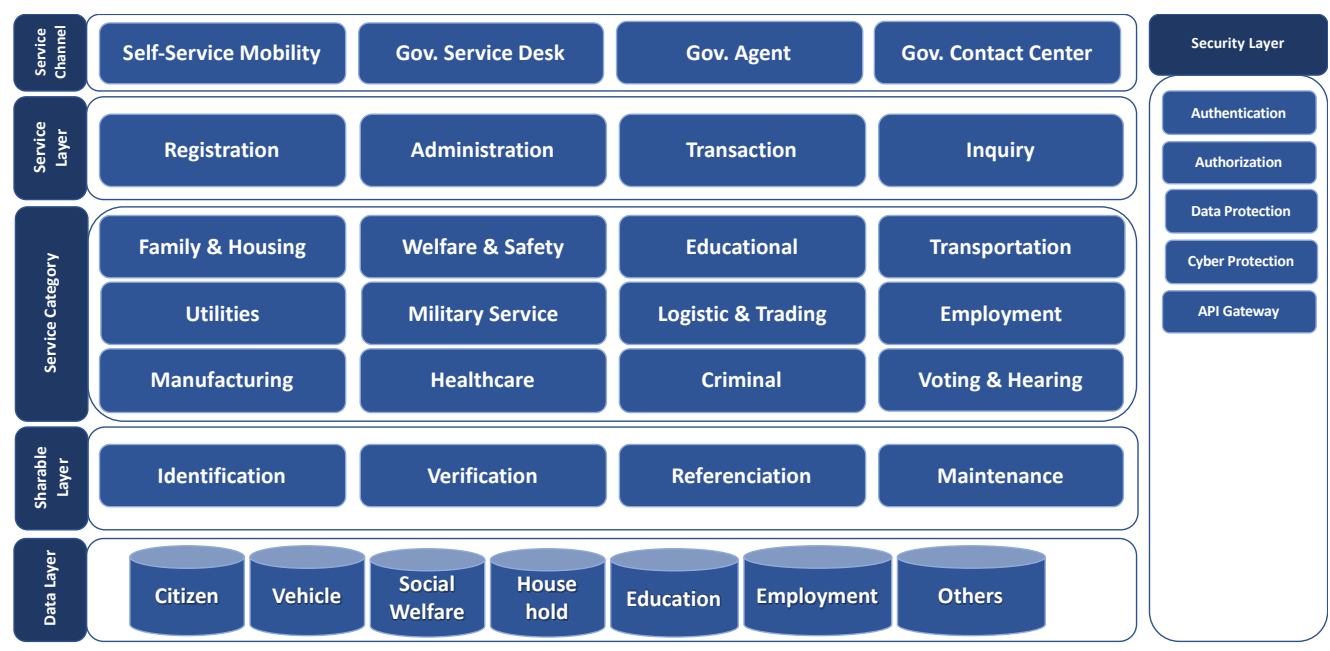

Figure 14. National Public Service Capabilities in Single Access.

Giving by the key focus of this case study, Figure 15 would demonstrate the high-level capabilities of Ministry of Transport, whereby the key fundamental of national capabilities has defined transportation being one of the key transformations roadmap for the service capability suited with Single Access objective as shown in Figure 14. The mission of defining target capabilities of Ministry of Transport is to transform all public services being 
served as self-service mobility directed to citizens. The collaboration as a sharable service for cross organization will be also considered as the target of improvement.

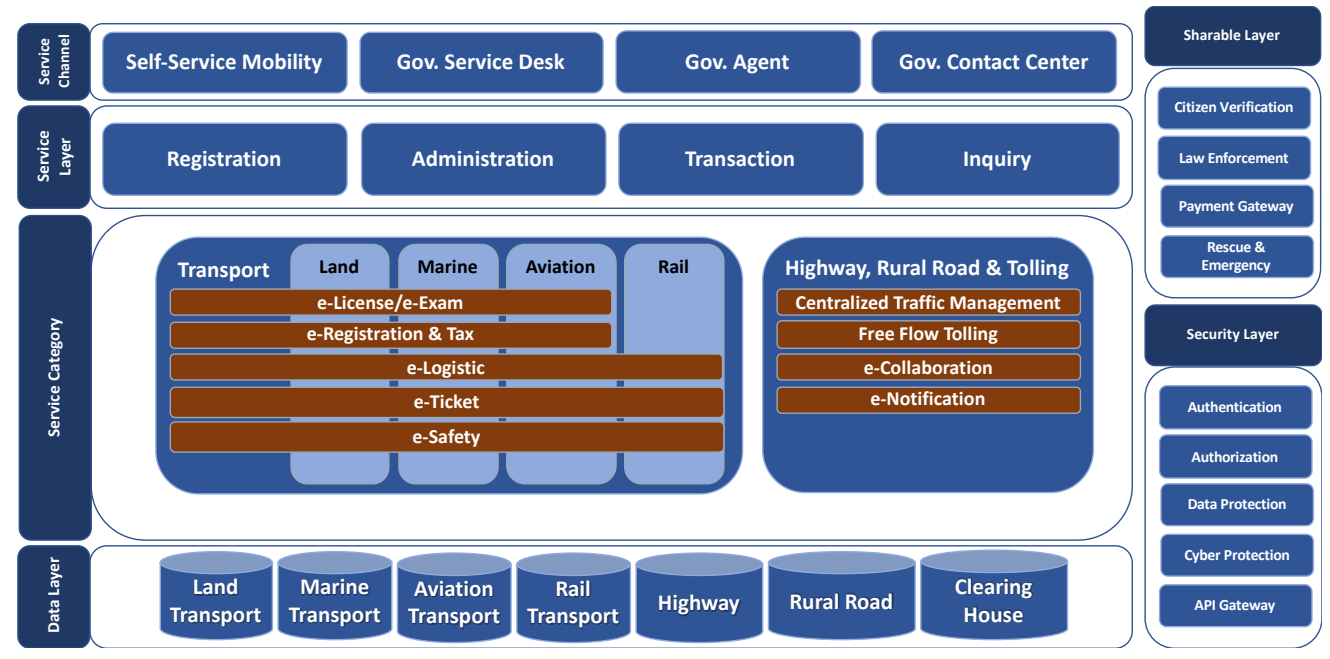

Figure 15. Target Capabilities of Ministry of Transport.

Figure 16 has described the target capabilities of the Department of Land Transport in alignment with the defined target capabilities of Ministry of Transport shown in Figure 15. This stage would consider as the first realization of the transformation roadmap. The following exercises all detailing will be conducted at the departmental level. The following exercises have been conducted.

- Performing an improvement of operation processes suiting with new expected target capabilities.

- Identifying key performances measurable in alignment with proposed process improvement.

- Conducting an exercise designing architecture landscape covering on these domains; information systems (application and data), information technology infrastructure, security, and integration layer. The key success factor of this exercise is to identify the state of action on all components of each domain whereby the type of actions is comprised with new acquiring, decommissioning, upgrading, and replacing.

- Conducting gap assessment exercise over the proposed architecture landscape of all domains.

- Conducting the project executable roadmap and prioritization according to the proposed architecture landscape of each domain.

- Conducting the detail design exercise of solution architecture.

- Conducting the designing of change management execution plan.

- Establishing the program management function for progressive monitoring and steered the strategic direction.

In summary, the proposed sustainable government enterprise architecture framework has demonstrated the differentiated exercise activities of establishing the enterprise architecture program for national public services that target to consolidate all public services serving into the single access platform with the strategic alignment. The critical path of this framework is to ensure all government offices and its agencies has fully aligned with the national strategic objective. All executable capabilities under the enterprise architecture exercise framework has been completely addressed, whereby all roadblocks or limitations are being properly resolved using officially legislation management. 


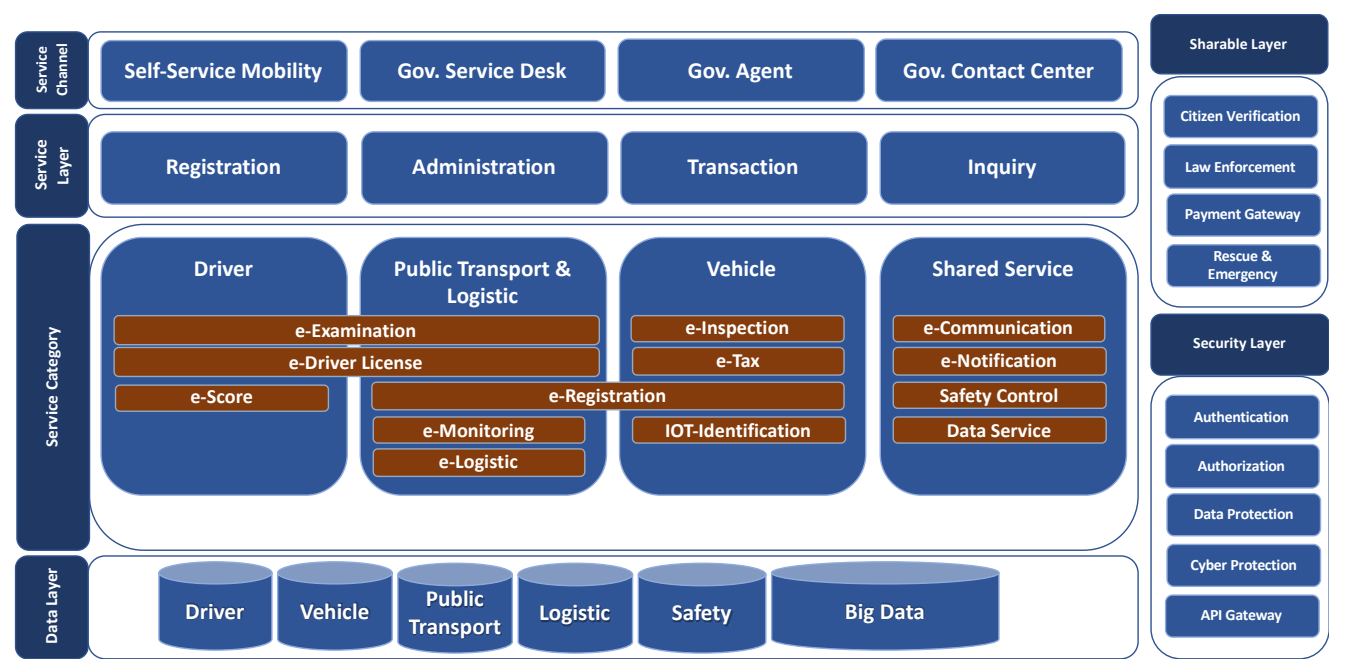

Figure 16. Target Capabilities of Department of Land Transport.

\section{Conclusions}

The purpose of this framework was designed for the group of developing countries who are going to implement the national enterprise architecture strategy in order to transform the fundamental national public services and information services ecosystem addressing the strategy of e-government having e-participation, e-document, and citizen centricity model as the guideline principal for their further innovation and digitalization. This article aims to propose a comprehensive view of the potentially compulsory components of enterprise architecture contribution to the government strategy of transformation in their proposed public services referring to the definition of e-government by the United Nations. The fundamental designed idea of this proposed framework has identified five keys principle which are (1) legislation support, (2) top-down target architecture, (3) architecture governance, (4) shared services, and (5) cross-organization collaboration that would be considered as the key critical success factors for achieving the exercise. The biggest challenge is to create cross-organization collaboration in concentration of a sharable perspective which might need to resolve the implication of legislation and regulation using EA Governance under the stage of Plan. The overall response of specific expert survey of this proposed framework has demonstrated the consensus responded at 90 percentage agreeable, which would strongly consider this framework applicable for group of developing countries as the baseline framework for their strategic planning and execution on the digitalized transformation. Thus, there is still some required tailoring to fit to the fundamental of each government and its operating model which might need to refine the framework upon appropriate.

Author Contributions: Conceptualization, M.T.; methodology, M.T.; validation, S.K.; formal analysis, M.T.; investigation, M.T. and S.K.; resources, M.T.; data curation, M.T.; writing-original draft preparation, M.T.; writing — review and editing, M.T. and S.K.; visualization, M.T.; supervision, S.K. All authors have read and agreed to the published version of the manuscript.

Funding: This research received no external funding.

Institutional Review Board Statement: The study was conducted according to the guidelines of the Declaration of Helsinki, and approved by the Institutional Review Board (or Ethics Committee) of Mahidol University (protocol code MU-CIRB 2020/219.2108 and date of approval 20 September 2020).

Informed Consent Statement: Informed consent was obtained from all subjects involved in the study.

Data Availability Statement: No new data were created or analyzed in this study. Data sharing is not applicable to this article.

Conflicts of Interest: The authors declare no conflict of interest. 


\section{References}

1. Simon, D.; Fischbach, K.; Schoder, D. Enterprise architecture management and its role in corporate strategic management. Inf. Syst. E-Bus. Manag. 2014, 12, 5-42. [CrossRef]

2. Hinkelmann, K.; Gerber, A.; Karagiannis, D.; Thoenssen, B.; van der Merwe, A.; Woitsch, R. A new paradigm for the continuous alignment of business and IT: Combining enterprise architecture modelling and enterprise ontology. Comput. Ind. 2016, 79, 77-86. [CrossRef]

3. Janssen, M. Sociopolitical Aspects of Interoperability and Enterprise Architecture in E-Government. Soc. Sci. Comput. Rev. 2012, 30, 24-36. [CrossRef]

4. Dang, D.D.; Pekkola, S. Systematic Literature Review on Enterprise Architecture in the Public Sector. Electron. J.e-Gov. 2017, 15, 130-154.

5. Pardo, T.A.; Nam, T.; Burke, G.B. E-Government Interoperability: Interaction of Policy, Management, and Technology Dimensions. Soc. Sci. Comput. Rev. 2012, 30, 7-23. [CrossRef]

6. Guijarro, L. Interoperability frameworks and enterprise architectures in e-government initiatives in Europe and the United States. Gov. Inf. Q. 2007, 24, 89-101. [CrossRef]

7. Gill, A.Q.; Smith, S.; Beydoun, G.; Sugumaran, V. Agile enterprise architecture: A case of a cloud technology-enabled government enterprise transformation. In Proceedings of the 18th Pacific Asia Conference on Information Systems (PACIS 2014), Chengdu, China, 24-28 June 2014; Association for Information Systems AIS Electronic Library: Atlanta, GA, USA, 2014 ; pp. 1-11.

8. Medini, K.; Bourey, J.P. SCOR-based enterprise architecture methodology. Int. J. Comput. Integr. Manuf. 2012, $25,594-607$. [CrossRef]

9. Janssen, M.; Estevez, E. Lean government and platform-based governance-Doing more with less. Gov. Inf. Q. 2013, 30, 1-8. [CrossRef]

10. The TOGAF Standard Version 9.2 Overview. Available online: https:/ /www.opengroup.org/togaf-standard-version-92-overview (accessed on 20 February 2020).

11. Zachman, J.A. The Zachman Framework for Enterprise Architecture; Zachman International: El Paso County, CO, USA, 2003.

12. The Office of Management and Budget. Federal Enterprise Architecture Framework Version 2; The Office of Management and Budget: Washington, DC, USA, 2013.

13. Eurostat. ESS EA Reference Framework; Eurostat, European Commission: Luxembourg, 2015.

14. Digital Government Development Agency. EGA Enterprise Architecture; Digital Government Development Agency (Public Organization): Bangkok, Thailand, 2015.

15. Lindström, A.; Johnson, P.; Johansson, E.; Ekstedt, M.; Simonsson, M. A survey on CIO concerns-do enterprise architecture frameworks support them? Inf. Syst. Front. 2006, 8, 81-90. [CrossRef]

16. Zachman, J.A. A framework for information systems architecture. IBM Syst. J. 1987, 26, 276-292. [CrossRef]

17. ISO/IEC/IEEE. ISO/IEC/IEEE 42020: Software, Systems and Enterprise-Architecture Processes; IEEE: Geneva, Switzerland, 2019.

18. Bittler, R.S.; Kreizman, G. Gartner Enterprise Architecture Process: Evolution 2005. Gart. Res. 2005. Available online: https://www.gartner.com/en/documents/486246/gartner-enterprise-architecture-process-evolution-2005 (accessed on 15 February 2020).

19. Fischer, R.; Aier, S.; Winter, R. A Federated Approach to Enterprise Architecture Model Maintenance. Enterp. Model. Inf. Syst. Archit. 2007, 2, 14-22.

20. De Vries, M. A framework for understanding and comparing Enterprise Architecture models. Manag. Dyn. 2010, 19, 17-29.

21. Cameron, B.H.; McMillan, E. Analyzing the Current Trends in Enterprise Architecture Frameworks. J. Enterp. Archit. 2013, $9,60-71$.

22. O'Leary, D.E. Enterprise ontologies: Review and an activity theory approach. Int. J. Account. Inf. Syst. 2010, 11, 336-352. [CrossRef]

23. Zhang, M.; Chen, H.; Luo, A. A Systematic Review of Business-IT Alignment Research with Enterprise Architecture. IEEE Access 2018, 6, 18933-18944. [CrossRef]

24. Gerow, J.E.; Grover, V.; Thatcher, J.; Roth, P.L. Looking Toward the Future of IT-Business Strategic Alignment through the Past. MIS Q. 2014, 38, 1159-1186. [CrossRef]

25. Charalabidis, Y.; Lampathaki, F.; Askounis, D.; Stassis, A. Shifting to Second Generation E-Government Interoperability Frameworks. In Proceedings of the International EGOV 2007 Conference, Regensburg, Germany, 3-7 September 2007.

26. European Union. New European Interoperability Framework; Office of the European Union: Luxembourg, 2017.

27. Charalabidis, Y.; Lampathaki, F.; Askounis, D. A Comparative Analysis of National Interoperability Frameworks. In Proceedings of the 15th Americas Conference on Information Systems 2009 (AMCIS 2009 Proceeding), San Francisco, CA, USA, 6-9 August 2009; Association for Information Systems AIS Electronic Library: Atlanta, GA, USA, 2009; pp. 1-11.

28. Guijarro, L. Semantic interoperability in eGovernment initiatives. Comput. Stand. Interfaces 2009, 31, 174-180. [CrossRef]

29. Hjort-Madsen, K.; Gøtze, J. Enterprise Architecture in Government-Towards a Multi-Level Framework for Managing IT in Government. In Proceedings of the 4th European Conference on e-Government, Castle Dublin, Ireland, 14 June 2004 ; pp. 365-374.

30. Ebrahim, Z.; Irani, Z. E-Government Adoption: Architecture and barriers. Bus. Process Manag. J. 2005, 11, 589-611. [CrossRef]

31. Lam, W. Barriers to e-government integration. J. Enterp. Inf. Manag. 2005, 18, 511-530. [CrossRef] 
32. Scholl, H.J.; Klischewski, R. E-Government Integration and Interoperability: Framing the Research Agenda. Int. J. Public Adm. 2007, 30, 889-920. [CrossRef]

33. Ojo, A.; Janowski, T.; Estevez, E. Improving Government Enterprise Architecture Practice-Maturity Factor Analysis. In Proceedings of the 2012 45th Hawaii International Conference on System Sciences, Maui, HI, USA, 4-7 January 2012; IEEE Computer Sociaty: Washington, DC, USA, 2012; pp. 4260-4269.

34. Islam, P. Citizen-centric E-Government: The Next Frontier. Harv. Kennedy Sch. Rev. 2007, 7, 103-108.

35. Charalabidis, Y.; Lampathaki, F.; Askounis, D. Unified Data Modelling and Document Standardization Using Core Components Technical Specification for Electronic Government Applications. J. Theor. Appl. Electron. Commer. Res. 2008, 3, 38-51. [CrossRef]

36. Lee, J.; Lee, H. Developing and validating a citizen-centric typology for smart city services. Gov. Inf. Q. 2014, 31, 93-105. [CrossRef]

37. Lim, S.; Malek, J.A.; Hussain, M.Y.; Tahir, Z. Citizen participation in building citizen-centric smart cities. Malays. J. Soc. Space 2018, 14, 42-53. [CrossRef]

38. UN. E-Government for the Future We Want, E-Government Survey 2014; Department of Economic and Social Affairs, United Nation: New York, NY, USA, 2014.

39. Dawes, S.S. The Future of E-Government; Center for Technology in Government, State University of New York: Albany, NY, USA, 2002.

40. Porwol, L.; Ojo, A.; Breslin, J.G. An ontology for next generation e-Participation initiatives. Gov. Inf. Q. 2016, 33, 583-594. [CrossRef]

41. Al-Dalou, R.; Abu-Shanab, E. E-Participation Levels and Technologies. Available online: https://www.researchgate.net/ publication/273632293_E-participation_levels_and_technologies (accessed on 23 February 2020).

42. Conroy, M.M.; Evans-Cowley, J. E-participation in planning: An analysis of cities adopting on-line citizen participation tools. Environ. Plan. C Gov. Policy 2006, 24, 371-384. [CrossRef]

43. Lapalme, J.; Gerber, A.; van der Merwe, A.; Zachman, J.; de Vries, M.; Hinkelmann, K. Exploring the future of enterprise architecture: A Zachman perspective. Comput. Ind. 2016, 79, 103-113. [CrossRef]

44. Stewart, G. Supply-chain operations reference model (SCOR): The first cross-industry framework for integrated supply-chain management. Logist. Inf. Manag. 1997, 10, 62-67. [CrossRef]

45. Cox, D.R.; Lewis, P.A.W. The Statistical Analysis of Series of Events; Chapman \& Hal: London, UK, 1996.

46. Blanc, D.L. E-Participation: A Quick Overview of Recent Qualitative Trends. Available online: https://www.un.org/ development/desa/ (accessed on 15 March 2020). 